\title{
Chapter 6 \\ Malthusian Assumptions, Boserupian Response in Transition to Agriculture Models
}

\author{
Carsten Lemmen
}

Keywords Sociometabolic transition · Population pressure · Innovation · Development framework

\subsection{Transitions to Agriculture}

The relationship between humans and their environment underwent a radical change during the last 10,000 years: from mobile and small groups of foragers to sedentary extensive cultivators and on to high-density intensive agriculture-based modern society; these transitions fundamentally transformed the formerly predominantly passive human user of the environment into an active component of the Earth system. The most striking impacts of these global transitions have only become visible and measurable during the last 150 years (Crutzen 2002; Crutzen and Stoermer 2000). Prior to this time frame, the use of forest resources for metal smelting in early Roman times and the extensive medieval agricultural system had already changed the landscape (Barker 2011; Kaplan et al. 2009); the global climate effects of these early extensive cultivation and harvesting practices are still under debate (Kaplan et al. 2011; Lemmen 2010; Ruddiman 2003; Stocker et al. 2011).

Transitions to agriculture occurred in almost every region of the world, with the earliest instances occurring in China and the Near East over 9,000 years ago (Kuijt and Goring-Morris 2002; Londo et al. 2006). More recent transitions occurred several 100 years ago in Australia and Oceania with the arrival of Polynesian and European immigrants (Diamond and Bellwood 2003). While each local transition can be considered revolutionary, the many diverse mechanisms, environments, and cultural contexts of each agricultural transition make it difficult to speak of one 'Neolithic revolution', as the transition to farming and herding was termed by V. G. Childe almost a century ago (Childe 1925). The transitions from foraging to farming were not simply one big step, but may have consisted of intermediary stages. Bogaard (2005) examines such transitions in terms of the land use system: she classifies the

C. Lemmen $(\triangle)$

Helmholtz-Zentrum Geesthacht, Institute for Coastal Research-System

Analysis \& Modeling, Ecosystem Modeling (KSE), Helmholtz-Zentrum Geesthacht,

Max-Planck-Strasse 1, 21502 Geesthacht, Germany

e-mail: carsten.lemmen@hzg.de 
progression as comprising inadvertent cultivation, horticulture, simple agriculture, and then advanced agriculture. Boserup (1965), however, classifies these stages by management practice: forest, bush, short fallow, annual cropping, and multi cropping.

In contemporary hunting-gathering societies, much less time is devoted to procuring food from hunting and gathering as compared to agriculture and herding (e.g., Sahlins 1972). In addition, less labour is required for long fallow systems compared to intensive multi-cropping agriculture (Boserup 1965). These phenomena raise the question: Why farm? Different explanations from archaeology (Barker 2011), demography (Turchin and Nefedov 2009), historical economy (Weisdorf 2005), and ecosystem modelling (Wirtz and Lemmen 2003), suggest that the answer lies in processes such as social reorganisation, the value of leisure, changing resources, and coevolutionary thresholds.

Malthus (1798) proposed what is arguably the simplest relationship, namely that more production sustains larger populations. With larger populations, more production is possible, thereby constituting a positive feedback loop, which ideally results in ever-increasing (geometric) growth and productivity. This ideal increase does not apply in a world with finite resources, as expressed by Malthus (1798, p. 4), who stated that: "Population, when unchecked, increases at a geometrical ratio. Subsistence increases only in an arithmetical ratio. A slight acquaintance with numbers will show the immensity of the first power in comparison with the second". Malthus identifies the need for positive and preventive checks to balance population increases with a limited capacity of resources.

It is important to note the reasons for productivity increases. First, the input of more labour increases productivity (Malthus 1798, p. 11), subject to the constraints of finite resources and diminishing returns. However, whereas Malthus focuses on extensive productivity increases, Boserup (1965) highlights the intensification component of productivity increases. Investments in a more intensive production system require significant additional labour, and the benefits of such investments are often small. To stimulate an investment in more intensive agriculture, Boserup requires population pressure.

Both Malthus $(1798,1826)$ and Boserup $(1965,1981)$ concentrate on the role of labour (and, later, division of labour and social/family organisation) and innovations that increase area productivity (such as storage or tools, requiring relatively more labour for harvesting, building, and tool processing). Both authors neglect the role of labour-independent innovation, or innovations that increase both area and labour productivity. These are innovations in the resources themselves, such as cultivation of higher-yielding grains or imported high yield varieties, or types of management such as water rights. Although this distinction may be ambiguous for certain innovations, it is used here conceptually. Labour-independent innovation can be stimulated by population diversity and density, both of which are positively related to population size. Darwin (1859, p. 156) wrote "The more diversified [...], by so much will they be better enabled to seize on many and widely diversified places in the polity of nature". Translated into the realm of innovation, Darwin's "seizing of places", or niche occupation, would be the realisation of technical and scientific opportunities. 
Regarding density as a stimulus of innovation, aggregation is understood to constitute a vehicle for technological and cultural change (Boyd and Richerson 1995; Smith 1776) ${ }^{1}$.

\subsection{Models of Population, Production, and Innovation}

In 1996, Ester Boserup reflected on the problems arising from the differences in terminology and methodology when comparing different models of development theories (Boserup 1996). She suggested a common framework to facilitate interdisciplinary cooperation based on six structures: Environment $(E)$, Population $(P)$, technology, occupational structure, family structure and culture. In this framework, she then interpreted the major works of Adam Smith, Thomas Malthus, Max Weber, Karl Marx, David Ricardo, and Neomalthusian thinking, as well as her own perspective on different stages of the developmental process.

For many of the theories and models discussed by Boserup in this framework, the partitioning into six structures can be simplified by (a) aggregating technology and occupational structure into a single entity technology $(T)$, and by (b) aggregating culture and family structure into a single entity culture $(C)$. Aggregating technology and occupational structure means that I assume here that changes in technology are equivalent to changes in organisation and that the location of technological change is the occupational sector. By aggregating family structure and culture, I assume that values and social conventions penetrate from the society into the family and are governed by similar dynamics. The reduced framework then consists of the following compartments: population, environment, technology, and culture (PETC, Fig. 6.1).

In this PETC framework, the model referring to Malthus (1798) involves only population and environment. Population growth exerts pressure on the environment, and failure to provide adequate resources from the environment acts as a positive check on population through higher mortality (Fig. 6.1a). Technology does not play a role in this simplest Malthusian model ${ }^{2}$. Culture in the form of preventive checkssuch as birth control - acts on population only in later versions of his theory (Malthus 1826). At its core remains "the dependent role he assigns to population growth" (Marquette 1997). D. Ricardo (1821) proposed that the incentive to intensify and develop technologies comes from a stimulus in population pressure. The demand for more land $(E)$, however, leads to declining marginal benefits of and negative feedback on innovation $(T)$ due to the high costs of renting the land (Fig. 6.1b). In Ricardo's work, population is the independent variable, and technology and environment are the dependent variables.

\footnotetext{
${ }^{1}$ This does not, however, explain the reason for a particular choice of one innovation over another (Sober 1992).

${ }^{2}$ Malthus considered the increase of carrying capacity by autonomously occurring inventions (Lee 1986), however, this was not discussed by Boserup (1996) in her model intercomparison.
} 

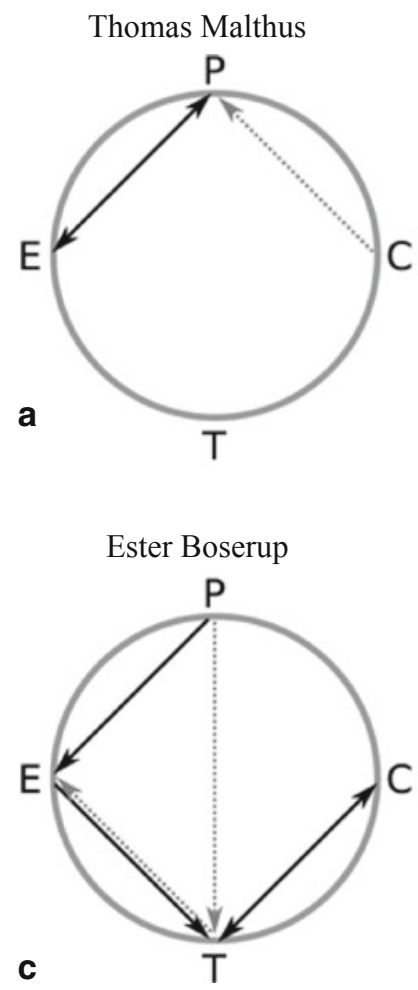

David Ricardo

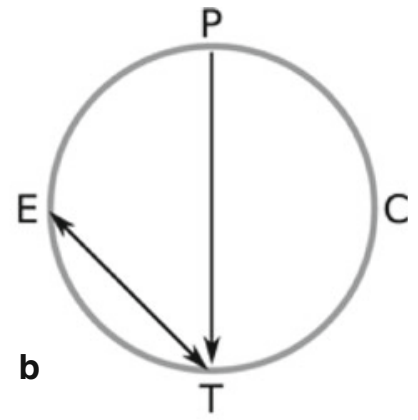

this paper

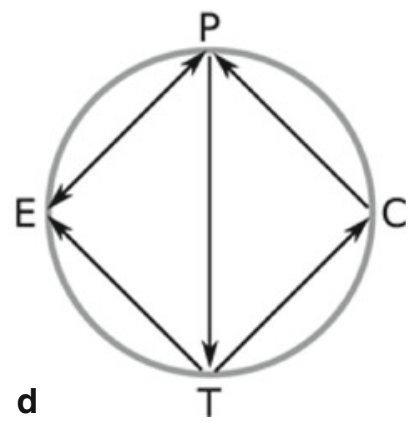

$\mathrm{P}=$ Population $\mathrm{T}=$ Technological level and occupational structure $\mathrm{E}=$ Environment $\mathrm{C}=$ Culture and family structure

Fig. 6.1 Four compartment framework for the interrelationship between population, environment, technology, and culture. Four economic theories are contrasted: the essays on the principles of population by T. Malthus $(1798,1826)(\mathbf{a})$, dotted line indicates the revised essay including culture change; D. Ricardo (1821)'s principles of economy (b), E. Boserup's $(1965,1981)$ theories for five transitions explained in Boserup (1996) (c), 1981 refinements shown as dotted lines; and the ecological model proposed in this chapter $(\mathbf{d})$. The framework is a simplification of the sixcompartment framework originally proposed by Boserup (1996)

Population is also the driving factor in Boserup's $(1965,1981)$ works. Of the six transitions considered by Boserup (1996), five transitions can be accommodated within my PETC framework as a succession of population, environment, technology, and culture: foraging to crop production, village development, Eastern hemisphere pastoralism, urbanisation, and industrialisation (Fig. 6.1c) ${ }^{3}$. In all of these transitions, population growth leads to pressure that derives from the limited environmental resources, which in turn stimulates technological and organisational change, and later results in cultural changes that are evident in cults, social hierarchies, women's

\footnotetext{
${ }^{3}$ The sixth transition — western European fertility decline—-follows a different path as a succession of technology, environment, culture, and last population; it is not considered here.
} 
status, and status symbols. Within this group of five transitions, Boserup's model of village development, in addition, has a direct population-technology link and allows for feedback regarding the land resources on occupational structure (dotted lines in Fig. 6.1c). Furthermore, her model of the foraging to farming transition includes a feedback from culture to organisational structure (not shown).

\subsection{A Combined Model and "Real" World Application}

Here, I suggest a different model of population development that considers the foraging to farming transition as an example (Fig. 6.1d). This model is a reduced form of the Global Land Use and technological Evolution Simulator (GLUES, described below), which has been operationally applied to a number of problems in archaeology and climate research (Kaplan et al. 2011; Lemmen and Wirtz 2010, 2012; Lemmen et al. 2011). The reduced model shares the functional characteristics of the full model, but it is not spatially explicit and the biogeographic and climate background is considered to be constant (see Appendix for equations).

Regarding the PETC framework, the dynamics between population, environment, technology and culture include the following (Fig. 6.1d, cmp. Boserup 1996, p. 509):

1. $P \rightarrow T \rightarrow P$ Population growth stimulates innovation by aggregation and diversity. Innovations in, e.g., health care, increase population;

2. $P \rightarrow E \rightarrow P$ Higher population uses increasingly more land for hunting and exerts pressure on the game stock, higher population densities damage the environment, and food shortage leads to reduced fertility (preventive check) or higher mortality (positive check). The rising capacity of the environment supports larger populations;

3. $T \rightarrow E$ More intensive foraging or farming strategies damage the environment, while efficiency gains lead to higher environmental capacity;

4. $T \rightarrow C$ Adoption of novel technologies induces changes in social structure where specialists and leaders or cults emerge;

5. $C \rightarrow P$ Family and social structure change reproduction rates.

Richerson and Boyd (1998) claim that basically all models that are rooted in ecology are Neomalthusian in essence, i.e., they can be characterised by a $P \rightarrow T \rightarrow E$ loop in Boserup's (1996) framework. This loop can be detected in my model, as well; in fact, historically, the model developed from ecosystem models of tree stands or algal communities (Wirtz and Eckhardt 1996). Unlike many other models, however, GLUES is based on coevolutionary dynamics of technologies and population and has no a priori information on whether there is an (Malthusian) "invention-pull view of population history" (Lee 1986, p. 98), or whether population is the (Boserupian) driver of development ${ }^{4}$. Applications of GLUES show an emergent emancipation of population development from the environment with increasing population and innovation (Lemmen and Wirtz 2010, 2012; Lemmen et al. 2011).

\footnotetext{
${ }^{4}$ See also Simon (1993) for a detailed discussion.
} 
GLUES mathematically resolves the dynamics of population density and three population-averaged characteristic sociocultural traits: technology $\left(T_{A}\right)$, share of agropastoral activities $(C)$, and economic diversity $\left(T_{B}\right)$. These traits are defined for preindustrial societies as follows:

1. Technology $\left(T_{A}\right)$ is a trait that describes the efficiency of food procurementrelated to both foraging and farming - and improvements in health care. In particular, technology as a model describes the availability of tools, weapons, and transport or storage facilities. It aggregates over various relevant characteristics of early societies and also represents social aspects related to work organisation and knowledge management. It quantifies improved efficiency of subsistence, which is often connected to social and technological modifications that run in parallel. An example of $\left(T_{A}\right)$ is the technical and societal skill of writing as a means for cultural storage and administration, with the latter acting as organisational lubricant for food procurement and its optimal allocation in space and among social groups. $\left(T_{A}\right)$ is labour-dependent.

2. A second model variable, $C$, represents the share of farming and herding activities, encompassing both animal husbandry and plant cultivation. It describes the allocation of energy, time, or manpower to agropastoralism with respect to the total food sector.

3. Economic diversity $\left(T_{B}\right)$ resolves the number of different agropastoral economies available to a regional population. This trait is in the full model closely tied to regional vegetation resources and climate constraints; in this reduced model, it denotes a labour-independent technology. A larger economic diversity offering different niches for agricultural or pastoral practices enhances the reliability of subsistence and the efficacy in exploiting heterogeneous landscapes.

The temporal change of each of these characteristic traits follows the direction of increased benefit for success (i.e., growth) of its associated population (Appendix Eq. 6.1).; this concept had been derived for genetic traits in the works of Fisher (1930) and was recently more stringently formulated by Metz and colleagues (Kisdi and Geritz 2010; Metz et al. 1992) as adaptive dynamics (AD). In AD, the populationaveraged value of a trait changes at a rate that is proportional to the gradient of the fitness function evaluated at the mean trait value. The AD approach was extended to functional traits of ecological communities (Merico et al. 2009; Wirtz and Eckhardt 1996) and was first applied to cultural traits of human communities by Wirtz and Lemmen (2003).

The adaptive coevolution of the food production system $\left\{T_{A}, T_{B}, C\right\}$ and population $P$ (Appendix Eqs. 6.1-6.4), which is at the heart of this model's implementation, was also found empirically by Boserup (1981, p. 15): "The close relationship which exists today between population density and food production system is the result of two long-existing processes of adaptation. On the one hand, population density has adapted to the natural conditions for food production [...]; on the other hand, food supply systems have adapted to changes in population density." 
PET trajectories

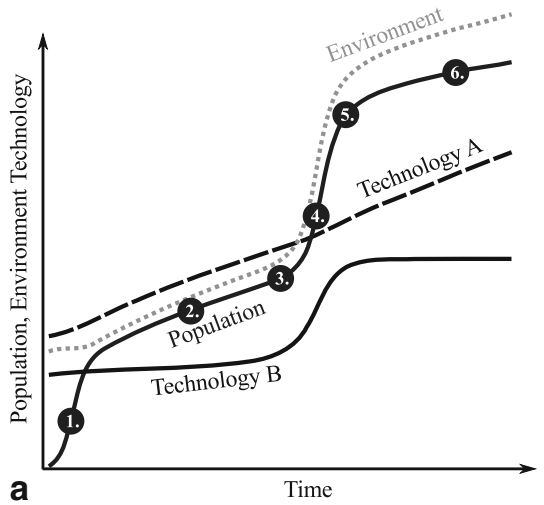

Innovativity vs. pressure

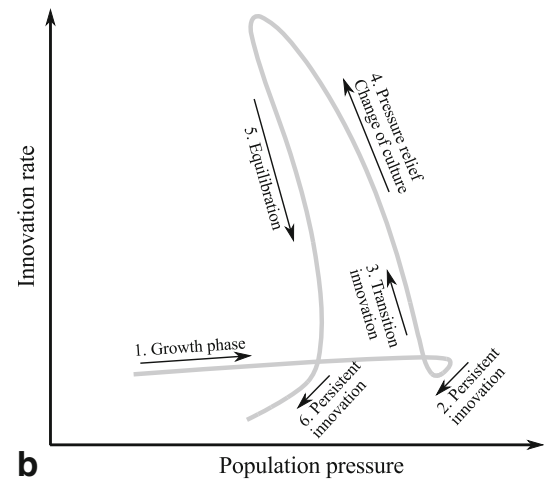

Fig. 6.2 Trajectories of population $P$, environment $E$, and technologies $T_{A}, T_{B}(\mathbf{a})$ and phase diagram of innovation rate versus population pressure, (b) from a simulation with a simplified version of the Global Land Use and technological Evolution Simulator. The trajectories describe the temporal evolution of population density, capacity denoted as environment, a labour-dependent technology $T_{A}$, and a labour-independent technology $T_{B}$. Numbers identify the different stages of development in the both diagrams. In the phase diagram $\mathbf{b}$, the innovation rate, derived as the cumulative change in $T_{A}+T_{B}$, is shown in relation to population pressure, calculated as $1-E+P$

\subsection{Innovation in Transitions to Agriculture}

The outcome of the coevolutionary model simulation with the reduced GLUES is shown in Fig. 6.2. I divided both the trajectories (temporal evolution of state variables, panel a) and the phase space (panel b) into six stages:

1. Growth phase: Beginning from a Malthusian perspective, and examining only population and environment (quantified here as the ecosystem capacity, i.e., the ratio of birth over mortality terms in the growth rate Eq. 6.3), population grows towards its capacity with diminishing returns as $P$ approaches $E$; this first phase spans only a short period of time but covers a large area in phase space;

2. Persistent innovation in technology $T_{A}$ and associated investments in tool making and administration allow sustained slow growth of population $P$ and alleviate the built-up population pressure; in contrast to the growth phase, the phase space coverage is very small, while the temporal extent of this phase is large.

3. Transition phase: rapid innovation in a labour-independent technology $T_{B}$ (e.g., domestication successes) leading to

4. Pressure relief, but this relief also induces also a cultural change (not shown);

5. Equilibration: Innovation slows but has led to a wider gap between $P$ and $E$ because of the investments made in manufacturing and organisation during the transition: accordingly, population pressure increases more slowly and up to a lower value than in the growth phase (1.);

6. Persistent innovation: corresponds to phase (2.) and is again characterised by persistent innovation in technology $T_{A}$ and a slow population pressure relief. 
Figure 6.2 provides key insight. What can be learned about the relationship between population pressure and innovation? (i) Innovation is greatest at high population pressure. (ii) In this model, innovation always occurs; at no time, the technology change is negative. (iii) The relationship between innovation and population pressure changes profoundly during the foraging-farming transition; three different regimes can be identified: (i) a positive relationship where acceleration of innovation corresponds to population pressure increases (phases 1,2,6), (ii) a negative relationship with pressure relief during accelerating innovation (phase 3,4 ), and (iii) a negative relationship with deceleration of innovation at increasing pressure (phase 5).

A superficial analysis would find that population pressure is the motor of innovation in this example: population increases seemingly precede the stepwise technological change (Fig. 6.2a). Only a detailed examination of the phase space (Fig. 6.2b) - especially at the transition phases 2 and 3-shows that innovation decelerates at very high population pressure and that the largest innovation occurs slightly below the highest population pressure. In fact, the driver in the transition depicted here is not population, but technology $y^{5}$. Only the different coevolutionary time scales of population growth (fast) and innovation (slow) yield the seemingly Boserupian, i.e., population driven, response.

The same mathematical model—plus spatial and biogeographic aspects-have been used to successfully simulate the many transitions to agriculture in Neolithic Europe (Lemmen et al. 2011), in good agreement with the radiocarbon record. Additionally, the transitions appear to be Boserupian with critical innovations occurring at high population pressure. If the numerical analysis had not been available (and proved that this phenomenon is in fact technology driven), as shown in the discretely sampled data from observations of technological change, one might erroneously conclude that this type of innovation was population driven.

\subsection{Conclusion}

I presented a reduced version of the Global Land Use and technological Evolution Simulator-a numerical model that is capable of realistically simulating regional foraging-farming transitions worldwide. The simulated-and possibly also observed - transitions are seemingly Boserupian, i.e., population driven: innovation is greatest when population pressure is high. Analytical examination of the model, however, shows that technological change is the driver of these phenomena and that, in the context of a simplified version of Boserup's (1996) framework in development theory, the model should be classified as Neomalthusian. I thus demonstrated that Boserupian appearance may be based on Malthusian assumptions; I caution not to infer too quickly a Boserupian mechanism for an observed real world system when its dynamics appears to be driven by population pressure.

\footnotetext{
${ }^{5}$ There would be no evolution of $T$ without $P$ due to the coevolutionary definition of the system. The dynamics of $T$, however, leads the dynamics of $P$ at the foraging-farming transition.
} 
Acknowledgments This study was partly funded by the German National Science Foundation (DFG priority project 1266 Interdynamik) and by the PACES program of the Helmholtz Gemeinschaft. The paper received great stimulus from discussions during the Ester Boserup Conference 2010 - A Centennial Tribute: Long-term trajectories in population, gender relations, land use, and the environment, November 15-17, 2010 in Vienna, Austria. I received helpful comments from two anonymous reviewers. GLUES is free and open source software and can be obtained from http://glues.sourceforge.net/.

\section{Appendix: The Reduced GLUES Model}

A coevolutionary system of population $P$ and characteristic traits $X \in\left\{T_{A}, T_{B}, C\right\}$ is defined by the evolution equations

$$
\begin{gathered}
\frac{d P}{d t}=P \cdot r, \\
\frac{d X}{d t}=\delta_{X} \cdot \frac{\partial r}{\partial X},
\end{gathered}
$$

where $r$ denotes the specific growth rate of population $P$, and the $\delta_{X}$ are variability measures for each $X$. Growth rate $r$ is defined as

$$
r=\mu \cdot\left(1-\omega T_{A}\right) \cdot\left(1-\gamma \sqrt{T_{A}} P\right) \cdot S I-\rho \cdot T_{A}^{-1} \cdot P,
$$

with coefficients $\mu, \rho, \omega$, and $\gamma$. In this formulation, the positive term including food production $S I$ is modulated by labour loss for administration $\left(-\omega T_{A}\right)$ and by overexploitation of the environment $\left(-\gamma \sqrt{T_{A}} P\right)$. Food production depends on the cultural system $C$ and available technologies as follows:

$$
S I=(1-C) \cdot \sqrt{T_{A}}+C \cdot T_{A} \cdot T_{B},
$$

where the left summand denotes foraging activities and the right summand agropastoral practice. To produce the results for Fig. 6.2, I assumed the following parameter values: $\mu=\rho=0.004, \omega=0.04, \gamma=0.12, \delta_{T_{A}}=0.025, \delta_{T_{B}}=0.9$, a variable $\delta_{C}=C \cdot(1-C)$, and initial values $P_{0}=0.01, T_{A, 0}=1.0, T_{B, 0}=0.8$, and $C_{0}=0.04$.

Open Access This chapter is distributed under the terms of the Creative Commons Attribution Noncommercial License, which permits any noncommercial use, distribution, and reproduction in any medium, provided the original author(s) and source are credited.

\section{References}

Barker, G. (2011). Archaeology: The cost of cultivation. Nature, 473, 163-164. http://dx.doi.org/10. 1038/473163a.

Bogaard, A. (2005). Garden agriculture and the nature of early farming in Europe and the Near East. World Archaeology, 37(2), 177-196. http://dx.doi.org/10.1080/00438240500094572. 
Boserup, E. (1965). The conditions of agricultural growth: The economics of agrarian change under population pressure. Chicago: Aldine.

Boserup, E. (1981). Population and technological change: A study of long-term trends. Chicago: University of Chicago Press.

Boserup, E. (1996). Development theory: An analytical framework and selected application. Population and Development Review, 22(3), 505-515.

Boyd, R., \& Richerson, P. J. (1995). Why does culture increase human adaptability? Ethology and Sociobiology, 16, 125-143. http://dx.doi.org/10.1016/0162-3095(94)00073-G.

Childe, V. G. (1925). The dawn of European civilization. London: Kegan Paul, Trench, Trubner.

Crutzen, P. J. (2002). Geology of mankind. Nature, 415, 23. http://dx.doi.org/10.1038/415023a.

Crutzen, P. J., \& Stoermer, E. F. (2000). The anthropocene. IGBP Newsletter, 41(1), 17-18.

Darwin, C. (1859). The origin of species (repr. 1958). Hayes Barton Press.

Diamond, J., \& Bellwood, P. (2003). Farmers and their languages: The first expansions. Science, 300(5619), 597-603. http://dx.doi.org/10.1126/science.1078208.

Fisher, R. A. (1930). The genetical theory of natural selection. Oxford: Clarendon Press.

Kaplan, J. O., Krumhardt, K. M., \& Zimmermann, N. (2009). The prehistoric and preindustrial deforestation of Europe. Quaternary Science Reviews, 28(27/28), 3016-3034. http://dx.doi.org/10.1016/j.quascirev.2009.09.028.

Kaplan, J. O., Krumhardt, K. M., Ellis, E. C., Ruddiman, W. F., Lemmen, C., \& Klein Goldewijk, K. (2011). Holocene carbon emissions as a result of anthropogenic land cover change. The Holocene, 21(5), 775-791. http://dx.doi.org/10.1177/0959683610386983.

Kisdi, É., \& Geritz, S. A. H. (2010). Adaptive dynamics: A framework to model evolution in the ecological theatre. Journal of Mathematical Biology, 61(1), 165-169. http://dx.doi. org/10.1007/s00285-009-0300-9.

Kuijt, I., \& Goring-Morris, N. (2002). Foraging, farming, and social complexity in the pre-pottery Neolithic of the southern Levant: A review and synthesis. Journal of World Prehistory, 16(4), 361-440. http://dx.doi.org/10.1023/A:1022973114090.

Lee, R. (1986). Malthus and Boserup: A dynamic synthesis. In D. Coleman \& R. Schofield (Eds.), The state of population theory: Forward from Malthus (pp. 96-130). Oxford: B. Blackwell.

Lemmen, C. (2010). World distribution of land cover changes during pre- and protohistoric times and estimation of induced carbon releases. Géomorphologie: Relief, Processus, Environnement, 2009(4), 303-312. http://dx.doi.org/10.4000/geomorphologie.7756.

Lemmen, C., \& Wirtz, K. W. (2010). Socio-technological revolutions and migration waves: Reexamining early world history with a mathematical model. In D. Gronenborn \& J. Petrasch (Eds.), The spread of the Neolithic to Central Europe, RGZM Tagungen (Vol. 4, pp. 25-38). Mainz: Römisch-Germanisches Zentralmuseum.

Lemmen, C., \& Wirtz, K. W. (2012). On the sensitivity of the simulated European Neolithic transition to climate extremes. Journal of Archaeological Science, http://dx.doi.org/ 10.1016/j.jas.2012.10.023. (online first).

Lemmen, C., Gronenborn, D., \& Wirtz, K. W. (2011). A simulation of the Neolithic transition in Western Eurasia. Journal of Archaeological Science, 38, 3459-3470. http://dx.doi. org/10.1016/j.jas.2011.08.008.

Londo, J. P., Chiang, Y.-C., Hung, K.-H., Chiang, T.-Y., \& Schaal, B. A. (2006). Phylogeography of asian wild rice, Oryza rufipogon, reveals multiple independent domestications of cultivated rice, Oryza sativa. PNAS, 103, 9578-9583. http://dx.doi.org/10.1073/pnas.0603152103.

Malthus, T. (1798). An essay on the principle of population. In F. Elwell (Ed.), A commentary on Malthus' 1798 essay on the principle of population as social theory (pp. 127-294). Lewiston: Mellen Press. (Commentary printed in 2001).

Malthus, T. (1826). An essay on the principle of population. Cambridge: Cambridge University Press (Edited by Patricia James [1989]).

Marquette, C. (1997). Turning but not toppling Malthus: Boserupian theory on population and the environment relationships. Working papers in development studies and human rights 16, Bergen. Norway: Chr. Michelsen Institute. 
Merico, A., Bruggeman, J., \& Wirtz, K. W. (2009). A trait-based approach for downscaling complexity in plankton ecosystem models. Ecological Modelling, 220(21), 3001-3010. http://dx.doi.org/10.1016/j.ecolmodel.2009.05.005.

Metz, J. A. J., Nisbet, R. M., \& Geritz, S. A. H. (1992). How should we define "fitness" for general ecological scenarios. Trends in Ecology and Evolution, 7, 198-202. http://dx.doi.org/ 10.1016/0169-5347(92)90073-K.

Ricardo, D. (1821). Principles of political economy (3rd ed.). London: John Murray.

Richerson, P., \& Boyd, R. (1998). Homage to Malthus, Ricardo, and Boserup: Toward a general theory of population, economic growth, environmental deterioration, wealth, and poverty. Human Ecology Review, 4, 85-90.

Ruddiman, W. F. (2003). The anthropogenic greenhouse era began thousands of years ago. Climatic Change, 61(3), 261-293. http://dx.doi.org/10.1023/B:CLIM.0000004577.17928.fa.

Sahlins, M. (1972). Stone age economics. New York: Aldine de Gruyter.

Simon, J. L. (1993). Economic thought about population consequences: Some reflections. Journal of Population Economics, 6(2), 137-152. http://dx.doi.org/10.1007/BF00178558.

Smith, A. (1776). The wealth of nations (repr. 1937). New York: Modern Library.

Sober, E. R. (1992). Darwin's nature. In J. Torrance (Ed.), The concept of nature (pp. 84-96). Oxford: Clarendon Press.

Stocker, B. D., Strassmann, K., \& Joos, F. (2011). Sensitivity of holocene atmospheric $\mathrm{CO}_{2}$ and the modern carbon budget to early human land use: Analyses with a process-based model. Biogeosciences, 8, 69-88. http://dx.doi.org/10.5194/bg-8-69-2011.

Turchin, P., \& Nefedov, S. (2009). Secular cycles. Princeton: Princeton University Press.

Weisdorf, J. L. (2005). From foraging to farming: Explaining the neolithic revolution. Journal of Economic Surveys, 19(4), 561-586. http://dx.doi.org/10.1111/j.0950-0804.2005.00259.x.

Wirtz, K. W., \& Eckhardt, B. (1996). Effective variables in ecosystem models with an application to phytoplankton succession. Ecological Modelling, 92, 33-53. http://dx.doi.org/10.1016/03043800(95)00196-4.

Wirtz, K. W., \& Lemmen, C. (2003). A global dynamic model for the neolithic transition. Climatic Change, 59(3), 333-367. http://dx.doi.org/10.1023/A:1024858532005. 